\title{
autêntica
}

\author{
ARTIGOS
}

\section{FORMAÇÃO DE PROFESSORES E EDUCAÇÃO NA PRISÃO: CONSTRUINDO SABERES, CARTOGRAFANDO PERSPECTIVAS}

Elenice Maria Cammarosano Onofre Camila Cardoso Menott

\begin{abstract}
RESUMO: O artigo que se apresenta tem a intenção de tecer algumas reflexões sobre formação de professores que atuam em espaços de privação de liberdade, considerando a complexidade da tarefa pedagógica e os saberes necessários para o exercício da docência entre as grades. Inserida em um espaço repressivo, a escola na prisão deve potencializar práticas emancipadoras de educação e o professor se constitui como ator fundamental nesse processo. Com base em referenciais teóricos que abordam as particularidades do contexto prisional e a formação de professores, as reflexões propostas sinalizam a necessária formação específica na modalidade da EJA e de formação continuada, com momentos reflexivos de compartilhamento de experiências com os pares, de ambientação para lidar com as contingências do espaço e de práticas educativas embasadas nas vivências dos educandos e que contribuam para a construção de projetos de vida.
\end{abstract}

PALAVRAS-CHAVE: Formação de professores; Docência entre as grades; Educação de Jovens e Adultos na prisão.

\section{TEACHER EDUCATION AND EDUCATION IN PRISON: BUILDING SKILLS, MAPPING PERSPECTIVES}

\begin{abstract}
The present article intends to provide a few insights into the education of teachers who act in places of deprived freedom, considering the intricacy of pedagogical tasks and the mastering needed to execute the teaching profession inside prison. Set in repressive circumstances, the school inside prison should enhance emancipatory practices the school training and the teacher represents a fundamental actor in this process. Based on theoretical references that approach the particularities of the prison context and on teachers education, the proposed reflections indicate the necessary specific basic training for the Youth and Adult Education programme (EJA) and for continuing education, through reflective moments of sharing experiences with their pairs, the adjustment to deal with the area contingencies and educational practices based on the experiences of students, which may contribute to the building of life projects.
\end{abstract}

KEYWORDS: Teacher's training; Teaching practice inside prison; Youth and adults education in prison. 


\section{INICIANDO AS REFLEXÕES}

O artigo que se apresenta é resultado de desdobramentos de investigações realizadas pelas autoras com o objetivo de analisar o papel da educação escolar em espaços de privação de liberdade e a formação de professores que atuam nas escolas das prisões.

A relevância do estudo se constituiu em registro de um momento da história da educação em prisões no Brasil, especificamente do estado de São Paulo, quando a Secretaria de Estado da Educação (SEE) assumiu, por determinação legal, as salas de aula das escolas das unidades prisionais e a formação dos professores.

Vale ressaltar, nestes apontamentos iniciais, que a missão histórica das prisões sempre foi a de recuperação e reintegração social do sujeito encarcerado, muito embora a arquitetura prisional e as rotinas a que os sentenciados são submetidos evidenciem os contrastes entre os objetivos das políticas públicas penitenciárias e as reais práticas desenvolvidas no interior dos estabelecimentos penais. O que se propõe, no entanto, é que a instituição prisional deve ir além da privação de liberdade, de um ambiente de repressão, regido por normas e regras rígidas de controle, uma vez que pode, através de algumas práticas educativas, desempenhar a essência de sua função, que é a de contribuir com a (re)integração do indivíduo à sociedade.

Em nosso entender, não basta capturar a pessoa da sociedade de pertencimento e inseri-la em outra com a justificativa de que o isolamento e a privação de liberdade são pilares suficientes para devolvê-la com outra conduta, se não houver espaços na prisão que contemplem o diálogo e a reflexão crítica sobre a realidade. Nesse sentido, a escola no interior das prisões pode ser uma ferramenta de reinserção social e de diminuição da reincidência criminal. Pode-se ressaltar também que alguns estudos, como os de Onofre (2007), Menotti (2013), Julião (2009), entre outros, sinalizam que os professores desempenham função relevante nesse espaço.

Contudo, algumas questões devem ser postas: em que medida os docentes estão preparados para lidar com a educação escolar de jovens e adultos em privação de liberdade e com as particularidades do contexto prisional?

Os apontamentos deste artigo têm a intenção de propor algumas reflexões sobre a docência entre as grades, considerando a complexidade dessa tarefa e o desenvolvimento de saberes necessários para o exercício da prática pedagógica.

\section{EDUCAÇÃO DE JOVENS E ADULTOS: DIREITO HUMANO SUBJETIVO}

Um dos papéis fundamentais da educação é promover uma sociedade com melhor qualidade de vida e formar sujeitos capazes de criar e recriar o espaço e a vida social onde estão inseridos. De acordo com as pesquisas realizadas pelo Instituto Brasileiro de Geografia e Estatística (IBGE) (2010), houve uma melhoria significativa na situação da educação no Brasil, porém o país ainda possui um total de 14,6 milhões de pessoas analfabetas, em sua maioria jovens e adultos.

Essa melhoria educacional e a diminuição dos índices de analfabetismo do país, principalmente em relação às crianças, são resultados da democratização do ensino público, em que "a escola pública para poucos, no passado, cedeu lugar à escola para muitos, no presente" (LEITE; DI GIORGI, 2004, p. 136). No entanto, ainda conforme Leite e Di Giorgi (2004), essa ampliação quantitativa não veio acompanhada de melhorias 


\section{autêntica}

qualitativas no ensino, dificultando a formação de sujeitos preparados para enfrentar os desafios do mundo contemporâneo.

De fato, há inúmeras críticas em relação à ampliação do acesso à educação, gerando uma discussão entre quantidade e qualidade do ensino. Beisiegel (2005) não nega que melhorias precisam ser realizadas na escola para que haja um ensino de qualidade para todos, mas defende que é preciso aceitá-la da forma em que se encontra atualmente, com a população que conquistou o direito que lhes foi negado por muitos anos, pois somente assim será possível pensar em uma escola com qualidade social. Para o autor, a democratização do ensino significou um indiscutível avanço, e "o ensino ganhou qualidade, uma vez que se abriu tendencialmente à totalidade da população" (BEISIEGEL, 2005, p. 121).

Ao analisar a situação carcerária do Brasil, fica evidente que grande parte das pessoas em privação de liberdade não teve acesso à educação durante a infância ou abandonou a escola por questões sociais, para trabalhar, ou por envolvimento com a criminalidade. Dados do Ministério da Justiça (apud CARREIRA; CARNEIRO, 2009, p.18) apontam que $8 \%$ dos aprisionados são analfabetos e $70 \%$ possuem ensino fundamental incompleto. Diante dessa realidade, a temática da Educação de Jovens e Adultos (EJA) em privação de liberdade vem, recentemente, sendo objeto de pesquisas acadêmicas que se dedicam a enfocar, prioritariamente, questões da educação como forma de (re)integração social, porém ainda são escassas as investigações que abordam a qualidade do ensino ministrado nas prisões e a docência entre as grades.

A EJA é uma modalidade da educação básica que se propõe a atender um público ao qual foi negado o direito à educação durante a infância e/ou adolescência. No entanto, para que se considere a EJA como uma modalidade educativa inscrita no campo do direito, faz-se necessário superar uma concepção dita compensatória, cujos principais fundamentos são o de recuperação de um tempo de escolaridade perdido no passado e também a ideia deque o tempo apropriado para o aprendizado é a infância e a adolescência.

Nessa direção, concordamos com Pereira (2011, p. 54), que é preciso buscar

[...] uma concepção mais ampla das dimensões tempo/espaço de aprendizagem, na qual educadores e educandos estabeleçam uma relação mais dinâmica com o entorno social e com as suas principais questões, considerando que a juventude e a vida adulta são também tempos de aprendizagens.

Os estudos de Paiva (1987) sinalizam que a educação de adultos aparece há muito pouco tempo no cenário da política educacional brasileira, e que somente na década de 1960 ocorre o surgimento de uma proposta metodológica específica para a alfabetização de adultos com o trabalho de Paulo Freire em Angicos (RN), inspirado nos princípios da educação libertadora e emancipadora, ou seja, a educação como ato político, como ato de conhecimento e como ato dialógico no descobrimento da razão de ser das coisas.

O Brasil possui instrumentos legais que fundamentam e institucionalizam a EJA como modalidade básica de ensino. A Constituição Federal promulgada em 05 de outubro de 1988 garante, através do Art. 205, que "a educação, direito de todos e dever do Estado e da família, será promovida e incentivada com a colaboração da sociedade, visando ao pleno desenvolvimento da pessoa, seu preparo para o exercício da cidadania e a sua qualificação para o trabalho" (BRASIL, 1988).

Por sua vez, o Parecer n. 11 (BRASIL, 2000), que regulamenta as Diretrizes Curriculares Nacionais para a EJA, representa um marco na consolidação legal da Educação de Jovens e Adultos no país. Através dele, busca-se 
compreender os aspectos da escolarização dos jovens e adultos no interior de um campo mais abrangente, estabelecendo um modelo pedagógico e agrupando funções e características dessa modalidade de ensino.

Segundo o Parecer $n .^{\circ} 11$, a EJA possui função reparadora, equalizadora e permanente. A função reparadora significa a entrada no campo dos direitos civis pela restauração do direito negado a uma escola de qualidade, ao reconhecimento de igualdade e ao acesso a um bem real, social e simbolicamente importante. A função equalizadora relaciona-se à igualdade de oportunidade, possibilitando aos indivíduos a inserção no mercado de trabalho e na vida cultural. A função permanente ou qualificadora busca garantir ao jovem e ao adulto da EJA qualidade de vida por meio da constante atualização dos conhecimentos.

Com a Declaração de Hamburgo (UNESCO, 1997), a educação de adultos torna-se mais que um direito, passando a ser a chave para o século XXI por possibilitar a todos o exercício da cidadania e a plena participação na sociedade. A alfabetização é um direito humano fundamental, conhecimento básico necessário a todos em um mundo em transformação, e também primordial para a participação dos indivíduos em atividades sociais, econômicas, políticas e culturais, além de ser requisito para a educação continuada ao longo da vida.

Nessa perspectiva, a EJA não deve ser compreendida como uma "segunda chance de educação", nem como a última oportunidade de fazer parte de uma sociedade letrada. Não deve ser encarada como um prêmio, tampouco como uma educação reduzida, oferecida àqueles que por razões sociais, políticas e familiares não tiveram acesso a ela durante a infância.

A Declaração Universal dos Direitos Humanos aprovada pela Assembleia Geral em 10 de dezembro de 1948, em sua resolução 217 A (III) (UNESCO, 1948), evidencia no Art. 26 que "toda pessoa tem direito à educação". De acordo com a Relatoria Nacional para o Direito Humano à Educação: Educação nas Prisões Brasileiras,

\begin{abstract}
As pessoas encarceradas, assim como todos os demais seres humanos, têm o direito humano à educação. A Declaração Universal dos Direitos Humanos reconhece o direito humano à educação em seu artigo 26 e estabelece que o objetivo dele é o pleno desenvolvimento da pessoa humana e o fortalecimento do respeito aos direitos humanos. Entende-se que os direitos humanos são universais (para todos e todas), interdependentes (todos os direitos humanos estão relacionados entre si e nenhum tem mais importância que outro), indivisíveis (não podem ser fracionados) e exigíveis frente ao Estado em termos jurídicos e políticos (CARREIRA; CARNEIRO, 2009, p. 10).
\end{abstract}

Dessa forma, os aprisionados estão privados do direito à liberdade devido ao delito que cometeram. Entretanto, mantêm a titularidade dos direitos básicos (integridade física, psicológica e moral), devendo o acesso à educação lhes ser assegurado.

Considerando a complexidade legal das questões da EJA no Brasil, a Lei de Execução Penal (Lei n. ${ }^{\circ}$ 7.210, de 11 de julho de1984) (BRASIL, 1984) prevê a garantia da assistência educacional do aprisionado como um direito (Art. 41, inciso VII). Os artigos de 17 a 21 da referida Lei estabelecem como essa assistência se dará, destacando a obrigatoriedade do ensino fundamental, ensino profissional, possibilidade de convênio com entidades públicas ou particulares e previsão de cada unidade prisional ser dotada de uma biblioteca. Entretanto, nesse documento se observa certa restrição à oferta educacional, visto que não são previstos acesso ao ensino médio e superior.

Com o intuito de investir na melhoria dessa realidade, foram homologadas as Diretrizes Nacionais para a oferta de educação para jovens e adultos em situação de privação de liberdade nos estabelecimentos penais 
(Resolução CNE/CEB n. ${ }^{\circ}$ 2, de 19 de maio de 2010), que regulamentam responsabilidades, financiamentos, ações complementares, envolvimento da comunidade e familiares, formação de educadores, entre outros aspectos (BRASIL, 2010). De acordo com essas Diretrizes Nacionais, as ações de educação nas unidades prisionais devem estar calcadas na legislação vigente do país e nos tratados internacionais firmados pelo Brasil no âmbito das políticas de direitos humanos e privação de liberdade (BRASIL, 2010).

Outro avanço considerável foi a Lei Complementar (Lei n 12.433, de 29 de julho de 2011) que alterou o artigo 126 da Lei de Execução Penal (Lei n. ${ }^{\circ}$ 7.210, de 11 de julho de 1984), permitindo que às pessoas em privação de liberdade diminuam a sua pena com base nas horas de estudo (BRASIL, 2011), e o Decreto 7.626, de 2 de novembro de 2011, que institui o Plano Estratégico de Educação no Âmbito do Sistema Prisional (PEESP), visando ampliar e qualificar a oferta de educação nas prisões (BRASIL, 2011). São diretrizes do PEESP:

\footnotetext{
I - promoção da reintegração social da pessoa em privação de liberdade por meio da educação;

II - integração dos órgãos responsáveis pelo ensino público com os órgãos responsáveis pela execução penal;
}

III - fomento à formulação de políticas de atendimento educacional à criança que esteja em estabelecimento penal, em razão da privação de liberdade de sua mãe (BRASIL, 2011).

Conforme explicitado, fica claro que a educação para jovens e adultos em privação de liberdade não deve ser encarada como benefício, mas sim como direito humano subjetivo previsto na legislação nacional e internacional. Estar preso significa perder os direitos de ir e vir livremente e ter seus direitos civis e políticos suspensos provisoriamente. Contudo, não implica a perda dos direitos ao respeito, à dignidade, integridade física, psicológica e moral e ao desenvolvimento pessoal e social, princípio central da educação nas prisões. No entanto, há também de se considerar que avanços significativos ocorreram no plano normativo, mas não se efetivaram no cotidiano das unidades prisionais. Esses ainda se constituem em desafio para estudiosos do tema e para gestores de políticas públicas educacionais.

\section{O PAPEL DOCENTE FRENTE AOS DESAFIOS DA EDUCAÇÃO ENTRE AS GRADES}

Nos últimos séculos, o mundo passou por transformações quem geraram possibilidades e riscos, além de níveis inéditos de exclusão. Diante dessa realidade e com a democratização do ensino, a escola vem sendo chamada a desempenhar novos papéis, mas, no entanto, sua estrutura, sua organização e seus profissionais não estão suficientemente preparados para os novos desafios e demandas.

De acordo com Di Giorgi (2004), isso aponta para a necessidade de mudança no modelo de escola e sugere que ela deve ter as seguintes características básicas:
a) ser produtora de conhecimento;
b) ter alto grau de autonomia;
c) assumir funções educativas mais amplas, por si mesma ou através de forte ligação com outras agências que também tenham caráter educativo;
d) promover, como papel a ser gradativamente assumido nas políticas públicas e legitimado no imaginário social, a dinamização cultural, social e eventualmente até econômica de seu entorno; 
e) o processo de formação dos educandos é, crescentemente, determinado, tanto no plano coletivo como individual, por eles próprios, única perspectiva pedagógica coerente com a formação de sujeitos (DI GIORGI, 2004, p. 12-13).

Essa proposta, embora necessária, está longe de ser atingida, ainda mais se estiver localizada em uma instituição total' , em que os indivíduos são isolados da sociedade e suas ações são normatizadas, como é o caso das prisões.

Quando a escola está inserida em um espaço repressivo, ela deve potencializar os processos educativos para além da educação escolar, e o professor é figura fundamental na construção de espaços em que o aprisionado tenha a oportunidade de significar o mundo como algo em constante transformação. Entretanto, para que a educação seja emancipadora, o educador necessita estar preparado para lidar com as particularidades de lecionar em uma prisão.

O ambiente prisional é contraditório, a começar por sua arquitetura, que separa e afasta o sujeito privado de liberdade da sociedade, "punindo-o e vigiando-o enquanto fala de educação e reinserção social" (ONOFRE, 2007, p. 24). Na realidade, os meios contradizem os fins, caminhando na contramão do pressuposto de conduziras pessoas para a prisão para serem educadas. Para a autora, "de todas as tarefas que a prisão deve executar, nenhuma é mais ambígua que a de transformar criminosos em não criminosos, pois os meios para atingi-la permanecem incertos" (ONOFRE, 2007, p. 24).

Atualmente a privação da liberdade é a forma por excelência para a punição de pessoas em conflito com a lei, possuindo a dupla finalidade de punir e reabilitar para o convívio social. Desde o século XIX a prisão se constituiu como a principal instituição responsável por conter o crime e sua proliferação. Contudo, da forma como está configurada em sua arquitetura - padrões normativos regidos por regras rígidas, atividades educativas isoladas, projetos pedagógicos elaborados sem a participação efetiva e compartilhada dos profissionais que atuam no espaço (professores, psicólogos, assistentes sociais, diretores, gestores) -, a instituição tem pouco contribuído para amenizar a criminalidade e muito menos para (re)integrar os sujeitos sob sua guarda à sociedade.

Nas palavras de Foucault (1977), a prisão possui diversos inconvenientes, e sabe-se que é perigosa, quando não inútil. "Entretanto não 'vemos' o que pôr em seu lugar. Ela é a detestável solução, de que não se pode abrir mão" (p. 208). Para o autor, os mecanismos internos de repressão e punição das prisões ultrapassam o castigo da "alma", regulando todos os movimentos do corpo do aprisionado, contribuindo para "fabricar novos criminosos ou para afundá-los ainda mais na criminalidade" (FOUCAULT, 1977, p. 131).

A punição prevista para os que infligem a lei é a privação de liberdade, porém, no interior dos estabelecimentos penais, os aprisionados sofrem com as difíceis condições de sobrevivência, denominadas por Sykes (1958) de "dores do cárcere". Essas limitações vão desde a privação de liberdade propriamente dita até a

\footnotetext{
1 Uma disposição básica da sociedade moderna é que o indivíduo tende a dormir, brincar e trabalhar em diferentes lugares, com diferentes coparticipantes, sob diferentes autoridades e sem um plano racional geral. $\mathrm{O}$ aspecto central das instituições totais pode ser descrito como a ruptura das barreiras que comumente separam essas três esferas da vida. Em primeiro lugar, todos os aspectos da vida são realizados no mesmo local e sob uma única autoridade. Em segundo lugar, cada fase da atividade diária do participante é realizada na companhia imediata de um grupo relativamente grande de outras pessoas, todas elas tratadas da mesma forma e obrigadas a fazer as mesmas coisas em conjunto. Em terceiro lugar, todas as atividades diárias são rigorosamente estabelecidas em horários, pois urna atividade leva, em tempo predeterminado, à seguinte, e toda a sequência de atividades é imposta de cima, por um sistema de regras formais explícitas e um grupo de funcionários. Finalmente, as várias atividades obrigatórias são reunidas num plano racional único, supostamente planejado para atender aos objetivos oficiais da instituição (GOFFMAN, 1996, p. 17).
} 


\section{autêntica}

privação de bens e serviços, de relações sexuais, de autonomia, de higiene, de identidade, de espaço e, em alguns casos, de alimentação.

Dessa forma, "a passagem por estabelecimentos penitenciários, além de estigmatizar, processa determinado aprendizado, que diz respeito muito mais à adaptação à vida em seu interior, do que fora dela" (PENNA, 2003, p. 61). Nesse sentido, a reincidência criminal, além de ser um sintoma das dificuldades enfrentadas pelo egresso na readaptação à vida civil, pode ser compreendida também como sintoma da sua adaptação à vida no cárcere.

Em outras palavras, o aprisionado se adapta às particularidades da instituição para diminuir sua permanência nesse espaço. No entender de Português (2001, p. 86), "a finalidade da pena de prisão é transmudada: no lugar de se nortear por (re)adaptar o indivíduo à sociedade, passa a se pautar por adaptar o indivíduo à vida carcerária". Assim, a partir do momento em que o sentenciado se adapta às normas e regras da prisão, entende-se que ele está apto para retornar à sociedade, acarretando em um grande equívoco, visto que o contexto prisional possui um sistema social diferenciado.

Pode-se concluir, portanto, que a prisão como uma instituição fechada que pretende devolver à sociedade indivíduos com outra conduta acaba gerando violência, visto que desestrutura física e psicologicamente o sujeito privado de liberdade à medida que não é capaz de suprir as carências dos encarcerados em face do ser humano livre (ONOFRE, 2007).

No dizer de Goffman (1996, p. 23),

[...] se a estada do internado é muito longa, pode ocorrer, caso ele volte para o mundo exterior, o que já foi denominado "desculturamento", isto é, "destreinamento", o que o torna temporariamente incapaz de enfrentar alguns aspectos de sua vida diária.

Assim sendo, a prisão como uma instituição total cria e mantém um tipo de tensão entre o mundo doméstico e o mundo institucional, e usa essa tensão como uma força estratégica no controle de seus internos (GOFFMAN, 1996). O autor caracteriza o processo de admissão na instituição como uma despedida e um começo que resultam em uma série de "rebaixamentos, degradações, humilhações e profanações do eu" (GOFFMAN, 1996, p. 24).

Ao chegar à prisão, de acordo com Onofre (2007), o aprisionado traz consigo sua concepção de si mesmo formada ao longo de suas experiências no mundo doméstico.

Nesse momento, ele é totalmente despido de seu referencial, pois ao entrar na prisão o sentenciado é desvinculado de todos os seus objetos pessoais, desde a roupa até os documentos. Aqueles sinais "clássicos" de pertencimento à sociedade são subtraídos: ao despir sua roupa e vestir o uniforme da instituição, o indivíduo começa a perder suas identificações anteriores para sujeitar-se aos parâmetros ditados pelas regras institucionais (ONOFRE, 2007, p. 13).

De fato, ao sair do seu mundo doméstico, a perda de propriedades torna-se importante devido aos sentimentos que o "eu" atribui para aquilo que possui. No entanto, a mais significativa dessas perdas é o nome, pois "qualquer que seja a maneira como é chamado, a perda do nome, constitui uma grande mutilação do eu" (ONOFRE, 2007, p. 13), causando nesse eu uma deterioração de sua identidade para a obtenção de outra. 
Em contrapartida, a escola é vista pelos aprisionados como espaço de comunicação, de convívio e interação entre as pessoas, onde podem se mostrar sem máscaras, configurando-se como "oportunidade de socialização, na medida em que oferece ao aluno outras possibilidades referenciais de construção de sua identidade e de resgate da cidadania perdida" (ONOFRE, 2007, p. 27). A escola entre as grades possui papel que vai além da transmissão de conhecimentos; é compreendida por seus educandos como possibilidade de vida longe da criminalidade.

As questões sinalizadas nesses apontamentos podem influenciar na construção da identidade das pessoas encarceradas, assim como na identidade do educador que atua nessas condições, visto que cada integrante da sociedade é diferente de outro e carrega consigo as marcas de sua própria história. Como formar professores para atuarem nesse contexto?

\section{A FORMAÇÃO INICIAL E CONTINUADA PARA A DOCÊNCIA ENTRE AS GRADES}

A formação docente pode ser dividida em duas etapas: a inicial (curso de graduação em Pedagogia ou demais licenciaturas) e a continuada (cursos realizados ao longo da carreira profissional).

Pode-se afirmar que os currículos nem sempre atendem à relação teoria-prática e que os estágios supervisionados não contribuem de maneira significativa para o início da docência, e esses fatores promovem o que se chama "choque de realidade" no início da carreira docente. No dizer de Gatti e Barreto (2009, p. 152), "a proporção de horas dedicadas às disciplinas referentes à formação profissional específica é de 30\%, ficando 70\% para outros tipos de matérias".

Ainda com base no estudo realizado pelas autoras, as disciplinas ofertadas nos cursos de Pedagogia e demais licenciaturas apresentam ementas preocupadas com a justificativa do "porque ensinar?". No entanto, as preocupações sobre "o quê ensinar" e "como ensinar" ainda ocorrem de maneira incipiente. Dessa forma,

Pode-se inferir que a parte curricular que propicia o desenvolvimento de habilidades profissionais específicas para a atuação nas escolas e nas salas de aula é bem reduzida. Assim, a relação teoria-prática, como reiteradamente proposta nos documentos legais e nas discussões da área, também se mostra comprometida desde essa base formativa (GATTI; BARRETO, 2009, p. 152).

Essa situação se agrava quando se trata de formação de competências na modalidade de Educação de Jovens e Adultos. Para Gatti e Barreto (2009), escassos cursos de Pedagogia e demais licenciaturas propõem em sua matriz curricular disciplinas voltadas para a reflexão e o aprofundamento sobre a EJA, sendo que na maioria dos casos são ofertadas como disciplinas optativas ou tópicos e projetos especiais.

Na perspectiva de Vieira (2008), é preciso compreender as particularidades dos sujeitos da EJA visando uma sociedade menos desigual, onde é de extrema importância a participação do Estado na tarefa de garantir o direito à educação para todos, inclusive para os grupos menos privilegiados, marginalizados e excluídos pela sociedade. Essa educação não deve ser baseada na compensação de uma eventual experiência de fracasso escolar, mas deve respeitar o conhecimento e a vivência que o aluno adulto traz consigo.

Concordamos com Vieira (2008) na relevância de se considerar a especificidade e a heterogeneidade do público da EJA, seus interesses, suas identidades, suas preocupações, necessidades e expectativas em relação à escola, além de suas habilidades e vivências, para assim construir uma proposta pedagógica. 
Portanto, é fundamental ter clareza de quem é esse sujeito com o qual convivemos cotidianamente para que os conteúdos a serem trabalhados façam sentido, tenham significado e, sobretudo, sejam elementos concretos na sua formação, instrumentalizando-o pelo domínio de conhecimentos que o habilite para uma intervenção significativa na sua realidade.

Nesse conjunto de preocupações, os professores, que nem sempre possuem uma formação inicial adequada, acabam encontrando dificuldades em lecionar na EJA, principalmente quando a escola se encontra em um ambiente repressivo e contraditório às práticas educativas, deixando, em muitos momentos, de promover discussões sobre o que realmente interessa para esse público. Na entrevista realizada por Vieira (2008, p. 40), o pesquisador Elionaldo Fernandes Julião deixa clara a ausência de preparo dos docentes:

\begin{abstract}
Uma pessoa da secretaria de educação, em uma visita, percebeu que os internos estavam pintando árvores de natal. A primeira coisa que ela fez foi se perguntar por que eles não estavam discutindo ou refletindo sobre o natal. Acabamos vendo que o professor não entende que é um espaço diferenciado, com necessidades específicas. A gente vê que é um processo de infantilização e de não reconhecimento desse sujeito. Ele não consegue reconhecer que é um adulto e que ele gostaria de estar dialogando sobre questões do cotidiano.
\end{abstract}

Em outras palavras, esses professores nem sempre sabem "o que ensinar" e "como ensinar" para pessoas adultas e, simultaneamente, não conhecem o contexto prisional e suas rotinas, uma vez que a prisão se caracteriza por ser uma instituição impermeável (GOFFMAN, 1996). Ou seja, para garantir o controle social, ela tem pouca ou nenhuma disposição em se relacionar, dialogar e ter contato com elementos externos.

O professor que atua na escola do sistema prisional necessita de formação específica em EJA, além de formação continuada que contribua na superação dos dilemas vivenciados na prisão, para realizar sua tarefa docente em prol de uma educação emancipadora, que se propõe a procurar a emersão ${ }^{2}$ das consciências, objetivando a inserção crítica do sujeito na realidade.

Como sinaliza o Art. 11 das Diretrizes Nacionais, para a oferta de educação nas prisões (BRASIL, 2010), os "educadores, gestores e técnicos que atuam nos estabelecimentos penais deverão ter acesso a programas de formação inicial e continuada que levem em consideração as especificidades da política de execução penal."

A educação é uma prática desveladora de conhecimento, mas para isso o educando necessita se assumir como tal, conscientizar-se como sujeito detentor de saberes, capaz de conhecer e atuar sobre o objeto de conhecimento. Igualmente, o educador não pode ignorar os saberes acumulados por seus educandos ao longo da vida. Dessa forma, "não é possível ao educador desconhecer, subestimar ou negar os 'saberes-de-experiência-feitos' com que os educandos chegam à escola" (FREIRE, 2005, p. 59). Para tanto, no dizer de Freire, a leitura da palavra sempre deve ser precedida pela leitura do mundo, partindo do saber do educando e de seu contexto cultural.

Vale à pena ressaltar que a educação não pode sozinha transformar criminosos em não criminosos. Nesse sentido, concordamos com Freire (1995, p. 96) que "a melhor afirmação para definir o alcance da prática educativa em face aos limites a que se submete é a seguinte: não podendo tudo, a prática educativa pode

\footnotetext{
${ }^{2}$ Para Paulo Freire (2005), há três possíveis graus de consciência, sendo a consciência crítica o terceiro estágio. Portanto, a imersão designa o primeiro grau de consciência e a emersão designa o processo de saída desse estágio, em busca do protagonismo social.
} 
alguma coisa". Conforme já explicitado, ela pode contribuir para a construção de sujeitos autônomos, críticos e reflexivos, capazes de visualizar alternativas para a própria vida, inclusive longe da criminalidade.

Diante dessas reflexões, pode-se afirmar que para haver uma educação de qualidade é relevante que o professor tenha competência para exercer sua profissão. Rios (2003) define competência como saber fazer bem nas dimensões técnica, de domínio dos conteúdos e estratégias para dar conta do trabalho, e política, que vai ao encontro daquilo que é desejável e estabelecido valorativamente para a atuação docente. Além disso, a dimensão técnica também carrega à ética.

A ética é mediação, mas também síntese da técnica e da política. Ela está expressa na escolha técnica e política dos conteúdos, dos métodos, do sistema de avaliação, etc., ou ela tem de desvendá-los. O educador enquanto profissional é portador da valoração em sua prática (RIOS, 2003, p. 67).

Para a autora, é preciso entender que o professor competente é aquele

[...] comprometido com a construção de uma sociedade justa, democrática, no qual saber e poder tenham equivalência enquanto elementos de interferência no real e organização das relações de solidariedade, e não de dominação entre os homens (RIOS, 2003, p. 65).

Dessa forma, o professor que atua nas escolas entre as grades deve ser comprometido com sua tarefa de educar, posicionando-se politicamente frente às questões sociais que envolvem seus alunos, acreditando que as aulas são ferramentas de transformação, de conscientização e de protagonismo. Esse professor deve estar preparado para lidar com o contexto prisional, consciente de seu papel para que a prática educativa seja consolidada nesse espaço, uma vez que, em muitos casos, parte dos funcionários dos estabelecimentos prisionais não se manifesta favoravelmente à escola para aprisionados, como se essa prática fosse um benefício e não um direito subjetivo.

Fica evidente que as particularidades do espaço prisional evidenciam as complexidades do ato pedagógico. Portanto, torna-se fundamental a formação inicial e continuada dos professores no sentido de refletir sobre a prática docente na EJA em diferentes contextos e a compreensão do espaço em que a escola está inserida, visando estabelecer uma estratégia educativa capaz de abranger a instituição e seus sujeitos na perspectiva de quem aprende (no caso, jovem ou adulto aprisionado) e nas características em que o ensino acontece (prisão) (ONOFRE, 2010).

\section{ALGUMAS CONSIDERAÇÕES: CARTOGRAFANDO POSSIBILIDADES}

Compreender o papel da educação escolar entre as grades e as particularidades de lecionar nesse contexto representa uma importante e necessária contribuição à literatura, visto que parte das pesquisas concluídas aborda questões relacionadas à escola e à reintegração social, sendo ainda escassos os estudos sobre a docência e seus desafios.

Por ser um ambiente singular, a prisão evidencia a complexidade do ato pedagógico, e os cursos de licenciatura possuem iniciativas tímidas na formação de educadores para atuarem em Educação de Jovens e Adultos, especialmente em relação às especificidades das escolas em estabelecimentos prisionais.

Diante dessa realidade, torna-se necessário refletir sobre a formação dos professores, uma vez que na sociedade contemporânea o trabalho desse profissional é cada vez mais essencial enquanto mediação 


\section{autêntica}

nos processos constitutivos da cidadania dos alunos, superando o fracasso e as desigualdades escolares (PIMENTA, 1999).

Almeja-se que os cursos de formação de professores sejam capazes de mobilizar

[...] os conhecimentos da teoria da educação e da didática necessários à compreensão do ensino como realidade social, e que devolva neles a capacidade de investigar a própria atividade para, a partir dela, constituírem e transformarem os seus saberes-fazeres docentes, num processo contínuo de construção de suas identidades como professores (PIMENTA, 1999, p. 18).

A identidade do professor não é um dado imutável, nem externo que se possa adquirir, mas sim um processo de construção do sujeito historicamente. Ser professor é uma das identidades de uma pessoa que possui outras identidades referentes aos papéis que desempenha na sociedade. Sendo assim, o conceito de identidade está amarrado à pergunta "Quem és?", e relaciona-se à consciência de pertencer a determinado grupo social, tendo a interferência da cultura e do meio como fatores de sua construção.

No entender de Pimenta (1999), a identidade se constrói também pelo significado que cada professor, enquanto ator e autor, pois organiza a tarefa docente através de seus "valores, de seu modo de situar-se no mundo, de sua história de vida, de suas representações, de seus saberes, de suas angústias e anseios, do sentido que tem em sua vida o ser professor" (PIMENTA, 1999, p. 19).

Portanto, os cursos de formação devem mobilizar os saberes de experiência para assim mediar o processo de construção de identidade dos professores, uma vez que esses saberes são produzidos no cotidiano docente, em um processo de reflexão sobre a própria prática.

Pode-se afirmar que a reflexão é a chave para uma prática educativa contextualizada e coerente com o que se espera das escolas nos dias atuais. A reflexão sobre a prática constitui o questionamento, e isso gera intervenções e mudanças. Refletir sobre a ação e na ação torna-se uma proposta metodológica para a construção da identidade do professor reflexivo.

De acordo com Ghedin (2002), há de se operar nos cursos de formação de professores uma mudança da epistemologia da prática para a epistemologia da práxis (reflexão-ação-reflexão), pois práxis é um movimento operacionalizado pela ação e reflexão, trazendo em seu interior a indivisibilidade entre teoria e prática.

Em oposição à racionalidade técnica que marcou o trabalho dos professores, o intelectual reflexivo pode ser entendido em um processo contínuo de formação, que passa pela inicial, nos cursos de graduação, e se estende ao longo da vida. Por outro lado, a formação docente deve ser também uma autoformação, em que os professores reelaboram os saberes iniciais, em diálogo com os saberes de experiência vivenciados nos contextos escolares. De acordo com Pimenta (1999, p. 29), é nesse confronto e na troca de experiências e práticas "que os professores vão constituindo seus saberes como praticum, ou seja, aquele que constantemente reflete na e sobre a prática".

Nessa perspectiva, o professor que atua em contextos diferenciados, como as prisões, e em uma modalidade de ensino ainda pouco discutida como a EJA, deve refletir diariamente sobre sua prática e sobre as questões sociais que envolvem seus educandos para que eles se tornem arquitetos de uma outra sociedade e conscientes do papel político da educação. 
A prisão, regida por normas e regras, tem caminhado na contramão de sua missão histórica de reinserção social das pessoas que ali se encontram, e a educação escolar pode contribuir para que se ela transforme em uma instituição educativa e inclusiva. Porém, um aspecto importante a considerar é que os professores, diante das demandas que Ihes são postas, assumam uma prática reflexiva e exerçam sua função de maneira compartilhada com seus pares. Os grupos de trabalho colaborativos podem ser possibilidades de promover nos espaços de privação de liberdade um projeto de formação continuada, em que o professor encontre apoio para continuar sua formação através do trabalho conjunto com seus pares e supervisores - processo esse gerado de dentro para fora, elaborado com base nas necessidades do contexto prisional (ONOFRE, 2010).

Não se trata, no entanto, de propor uma educação escolar específica para o contexto prisional. Não se pode, também, ser a mesma educação que já excluiu os estudantes. Concordamos com Pereira (2014, p. 4) quando afirma que é preciso respeitar as singularidades do espaço e "motivar essas pessoas a ponto de ver na educação uma possibilidade de emancipação, ainda na condição de encarceradas". De igual forma, não estamos sinalizando que para ser professor em escolas de unidades prisionais há de se ter uma formação diferenciada, uma vez que estamos diante de uma escola pública como as outras, com professores da rede pública de ensino e com estudantes de EJA, com as singularidades dessa modalidade de ensino.

Certamente, as reflexões que procuramos construir indicam enfrentamentos de diferentes naturezas quando se trata da educação escolar em prisões e podem anunciar possibilidades de significar a escola e suas práticas, de forma a atender os anseios de jovens, adultos e professores, protagonistas desse espaço educativo.

Em linhas gerais, compartilhamos com as ponderações de estudiosos da EJA na relevância de sua implementação como política pública e gratuita, da oferta de alfabetização e da continuidade de escolarização na medida necessária para atender ao seu público nos espaços e nas demandas específicas, da qualidade pedagógica de suas escolas, da formação dos professores e do estabelecimento de critérios transparentes para o funcionamento de todas as escolas de EJA, independentemente dos espaços onde estejam inseridas.

Vivemos momentos de instabilidades que significam alerta para o espaço da educação escolar, pois notamos que, mais uma vez, a descontinuidade nas políticas deixa registrado o receituário dos organismos internacionais para a educação, atrelando-a ao mercado e transferindo-a para a esfera privada.

Por sua vez, a palavra de ordem "privatização" parece ecoar indício fértil para os espaços de privação de liberdade. Manter fronteiras abertas pode bloquear, por conta da porosidade da instituição prisão, os avanços conseguidos, mesmo que lentamente, para a educação ali materializada - com professores da rede pública, flexibilidade nas matrizes curriculares, cursos de formação de professores (mesmo que ainda pontuais), aumento do número das salas de aula (mesmo que improvisadas), ensino presencial e material didático (ainda que em produção pequena).

O desafio para a resistência está posto: as pessoas podem e mudam o curso de suas vidas; as narrativas de jovens e adultos escolarizados nas prisões revelam sonhos e aspirações conquistados na escola, em aulas presenciais com seus professores; as experiências bem-sucedidas de professores estão registradas em estudos acadêmicos nos últimos anos. A ética do cuidado com o outro foi semeada! 


\section{DOCENTE}

\section{autêntica}

\section{REFERÊNCIAS}

BEISIEGEL, C. de R. A qualidade do ensino na escola pública. Brasília: Líber Livro, 2005.

BRASIL. Constituição (1988). Constituição da República Federativa do Brasil, 1988. Brasília: Senado Federal, Centro Gráfico, 1988.

BRASIL. Decreto n. ${ }^{\circ}$ 7.626, de 2 de novembro de 2011.

BRASIL. Lei de execução penal n. ${ }^{\circ}$ 7.210, de 11 de julho de 1984.

BRASIL. Parecer CNE/CEB n. ${ }^{\circ}$ 11/2000: Diretrizes Curriculares Nacionais para a Educação de Jovens e Adultos. Brasília: MEC, 2000.

BRASIL. Lei nº 12.433, de 29 de junho de 2011.

BRASIL. Resolução CNE/CEB n. ${ }^{\circ}$ 2/2010: Diretrizes Nacionais para a oferta de educação de jovens e adultos em situação de privação de liberdade nos estabelecimentos penais. Brasília: MEC/CNE/SECAD, 2010.

CARREIRA, D.; CARNEIRO, S. Relatoria nacional para o direito humano à educação: educação nas prisões brasileiras. São Paulo: Plataforma DhESCA Brasil, 2009.

CARVALHO, O. F. de. Entre celas e salas de aula: um estudo sobre experiências educacionais de educadores presos no sistema prisional paulista. 2014. Tese (Doutorado em Educação) - Programa de Pós-Graduação em Educação, Universidade Federal de Uberlândia, Uberlândia, 2014.

DI GIORGI, C. A. G. Uma outra escola é possível! Uma análise radical da inserção social e da democracia na escola do mundo globalizado. Campinas: Mercado de Letras/Associação de Leitura do Brasil, 2004.

FREIRE, P. Pedagogia do oprimido. 49ª edição. Rio de Janeiro: Paz e Terra, 2005.

FREIRE, P. Política e educação. São Paulo: Cortez, 1995.

FOUCAULT, M. Vigiar e punir. Tradução de Lígia M. Pondé Vassallo. Rio de Janeiro: Vozes, 1977.

GATTI, B. A.; BARRETO, E. S. de S. Professores do Brasil: impasses e desafios. Brasília: UNESCO, 2009.

GHEDIN, E. Professor reflexivo: da alienação da técnica à autonomia da crítica. In: PIMENTA, S. G; GHEDIN, E. (Orgs.). Professor reflexivo no Brasil: gênese e crítica de um conceito. São Paulo: Cortez, 2002. p. 129-150.

GOFFMAN, E. Manicômios, prisões e conventos. Tradução de Dante Moreira Leite. $5^{a}$ edição. São Paulo: Perspectiva, 1996

IBGE. Censo demográfico 2010. Disponível em:<www.censo2010.ibge.gov.br/primeiros_dados_divulgados>. Acesso em: 13 jan. 2014.

JULIÃO, E. F. A ressocialização através do estudo e do trabalho no sistema penitenciário brasileiro. 2009. Tese (Doutorado em Educação). Instituto de Filosofia e Ciências Humanas. Programa de Pós-graduação em Ciências Sociais. Universidade do Estado do Rio de Janeiro - UERJ, Rio de Janeiro, 2009. 


\section{autêntica}

LEITE, Y. U. F; DI GIORGI, C. A. G. Saberes docentes de um novo tipo na formação profissional do professor: alguns apontamentos. Revista Educação, Universidade Federal de Santa Maria, v. 29, n. 02, p. 135-145, 2004.

MENOTTI, C. C. O exercício da docência entre as grades: reflexões sobre a prática de educadores do sistema prisional do estado de São Paulo. 2013. Dissertação (Mestrado em Educação) - Programa de Pós-Graduação em Educação, Universidade Federal de São Carlos, São Carlos, 2013.

ONOFRE, E. M. C. Escola da prisão: espaço de construção da identidade do homem aprisionado? In: ONOFRE, E. M. C. (Org.). Educação escolar entre as grades. São Carlos: EdUFSCar, 2007. p. 11-28.

ONOFRE, E. M. C. Docência na prisão: professores duplamente iniciantes, aprendendo com os pares e com o contexto. In: Congreso Internacional sobre profesorado principiante e inserción profesional a la docência, Buenos Aires. Anais... Buenos Aires: Ministerio de Educación de la Nación, 2010. p. 1-11.

PAIVA, V. P. Educação Popular e Educação de Adultos. 5a edição. São Paulo: Loyola, 1987.

PENNA, M. G. de O. O ofício do professor: as ambiguidades do exercício da docência por monitores-presos. 2003. Dissertação (Mestrado em Educação) - Programa de Pós-Graduação em Educação, Pontifícia Universidade Católica, São Paulo, 2003.

PEREIRA, A. A educação-pedagogia no cárcere, no contexto da pedagogia social: definições conceituais e epistemológicas. Revista de Educação Popular, Uberlândia, v. 10, p. 38-55, 2011.

PEREIRA, C. M. Educação de jovens e adultos: uma contribuição à discussão da proposta pedagógica de rede estadual de ensino. Rio Negro, 2014. p. 1-16. Disponível em: <http://www.diaadiaeducacao.pr.gov.br/ portals/pde/arquivos/983-4.pdf> Acesso em: 10 maio 2016.

PIMENTA, S. G. Formação de professores: identidade e saberes da docência. In: PIMENTA, S. G. (Org.). Saberes pedagógicos e atividade docente. São Paulo: Cortez, 1999. p. 15-34.

PORTUGUÊS, Manoel Rodrigues. Educação de adultos presos: possibilidades e contradições da inserção da educação escolar nos programas de reabilitação do sistema penal do estado de São Paulo. 2001. Dissertação (Mestrado em Educação) - Programa de Pós-Graduação em Educação, Universidade de São Paulo, São Paulo, 2001.

RIOS, T. A. Ética e competência. 13ª edição. São Paulo: Cortez, 2003.

SYKES, G. M. The society of captives: a study of a maximum security prison. Princeton: Princeton University Press, 1958.

UNESCO. Conferência internacional sobre a educação de adulto. Declaração de Hamburgo: agenda para o futuro. Brasília: SESI/UNESCO, 1997.

UNESCO. Declaração universal dos direitos humanos. Resolução 217 A (III) de 10 dez. 1948. Disponível em: <www.mj.gov.br/sedh/ct/legis_intern/ddh_bib_inter_universal.htm>. Acesso em: 13 jan. 2014.

VIEIRA, E. de L. G. Trabalho docente: de portas abertas para o cotidiano de uma escola prisional. 2008. Dissertação (Mestrado em Educação) - Programa de Pós-Graduação em Educação, Pontifícia Universidade Católica, Rio de Janeiro, 2008. 